\title{
REFLEJO EN UN ESTUDIO DE CORPUS DE LA EVOLUCIÓN Y FRECUENCIA DE LA DIALEFA EN LA VERSIFICACIÓN ESPAÑOLA \\ EVOLUTION AND FREQUENCY OF DIALEFA IN SPANISH POETRY ACCORDING TO A CORPUS ANALYSIS
}

\author{
Antonio Alcoholado Feltstrom \\ Universitat Jaume I
}

\section{Resumen}

Entre los fenómenos métricos, la dialefa ha experimentado una evolución desafortunada en la versificación española desde el s. XIII hasta nuestros días, pasando de tener carácter de canon en la escansión del mester de clerecía a aparecer en una proporción de escaso valor en comparación con su fenómeno adverso, la sinalefa. Este trabajo atiende a dicha evolución y sus implicaciones preceptivas según se reflejan en el análisis de un corpus de 18471 versos.

PALABRAS ClAVE: hiato, antihiatismo, fenómenos métricos, versificación, preceptiva.

\section{Abstract}

Among the meter phenomena, dialepha (hiatus in between words) has evolved in an unsuccessful fashion ever since the $13^{\text {th }}$ Century to nowadays, changing roles from being a scansion rule for the Ministry of Clergy poets to becoming an exception if compared to its opposite phenomenon, synalepha. This paper focuses on the said evolution and its normative implications according to its reflection in a corpus built on 18471 lines.

KEY wORDs: hiatus, anti-hiatus, meter phenomena, meters, precepts.

\section{INTRODUCCIÓN}

Este trabajo atiende al valor preceptivo y numérico de la dialefa, entre los restantes fenómenos métricos, según se refleja en un corpus de 18471 versos regulares 
extraídos de la Antología Cátedra de Poesía de las Letras Hispanas en su edición de $2012^{1}$.

Este estudio del valor de la dialefa en la versificación española se desarrolla a lo largo de cinco apartados a continuación, comenzando con la presentación de nuestro objeto de estudio, el fenómeno métrico de la dialefa, seguida de las observaciones preceptivas de varios tratadistas a partir del siglo XVIII y de la introducción de las características del corpus seleccionado; tras el comentario y explicación de los datos obtenidos del análisis métrico del corpus, se ofrece una breve recapitulación del estudio.

\section{LA DIALEFA ENTRE LOS FENÓMENOS MÉTRICOS}

Tradicionalmente se ha llamado licencias poéticas a ciertos recursos de los que se vale el poeta en la versificación, consistentes en alteraciones del número de sílabas gramaticales de un verso. Se distinguen dos tipos: los metaplasmos, que modifican la forma de una palabra artificialmente, mediante adición o sustracción de sonidos, a los que no atendemos en el presente estudio, y las licencias que tienen que ver con combinaciones de vocales. Se postula desde la versificación que el poeta no puede utilizar estas últimas a su antojo, sino solamente siguiendolas pautas dela pronunciación corriente ${ }^{2}$, puesto que, como explicó Bello³: «se verifican no solo en poesía, sino en el lenguaje ordinario, de cuya pronunciación no es lícito al poeta alejarse».

Puesto que persiguen reflejar las pautas de la pronunciación corriente, se ha recriminado la denominación de licencias para procesos normales de la realización oral $^{4}$. Por tanto, no las referiremos en este trabajo como licencias sino como fenómenos, según los denominan Spang ${ }^{5}$, Quilis ${ }^{6}$, Domínguez Caparrós ${ }^{7}$ y la Real Academia ${ }^{8}$.

Los fenómenos métricos son cuatro: sinéresis, sinalefa, diéresis y dialefa.

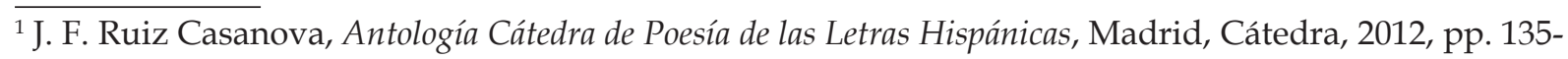
1163.

${ }^{2}$ J. Domínguez Caparrós, Diccionario de métrica española, Madrid, Alianza, 2001, pp. 113, 204, 217, 400.

${ }^{3}$ A. Bello, Principios de ortología y métrica de la lengua castellana, Santiago de Chile, La Opinión, 1835, p. 55.

${ }^{4}$ R. Jaimes Freyre, Leyes de la versificación castellana, La Paz, Imprenta Artística, 1919, p. 95. R. Balbín, Sistema de rítmica castellana, Madrid, Gredos, 1968, p. 84. K. Spang, Ritmo y versificación. Teoría y práctica del análisis métrico y rítmico, Murcia, Universidad de Murcia, 1983, p. 35. E. Torre, El ritmo del verso: estudios sobre el cómputo silábico y la distribución acentual a la luz de la métrica comparada, en el verso español moderno, Murcia, Universidad de Murcia, 1999, pp. 39-40.

${ }^{5}$ K. Spang, Ritmo y versificación [...], ob. cit., p. 35.

${ }^{6}$ A. Quilis, Métrica española, Barcelona, Ariel, 1984, p. 47.

${ }^{7}$ J. Domínguez Caparrós, Diccionario de métrica española, ob. cit., p. 217.

${ }^{8}$ Real Academia Española, Asociación de Academias de la Lengua Española, Nueva gramática de la lengua española. Fonética y fonología, Barcelona, Espasa, 2011, p. 353. 
Sintetizando las explicaciones de algunos de los autores consultados en este estudio", la dialefa consiste en la articulación en dos sílabas distintas de dos vocales cualesquiera en posición de contigüidad, aunque gramaticalmente constituyan diptongo, entre vocales inicial y final de palabras vecinas (pronunciación separada de /i/ y /a/ en el caso de «mi alma», por ejemplo). El fenómeno métrico opuesto, la sinalefa, consiste en la pronunciación en una misma sílaba métrica de dos vocales contiguas, que gramaticalmente no constituyen diptongo y por lo tanto se considera que habrían de articularse en sílabas distintas, según la autoridad normativa ${ }^{10}$. La diéresis y la sinéresis constituyen sus correlaciones en interior de palabra.

Numerosos autores, no solo en el campo de la métrica sino también en el de la gramática, extienden el concepto de sinalefa al de diptongo, cuando en un enunciado se da entre palabras distintas una secuencia de vocal cerrada átona con media o abierta (caso, por ejemplo, de mi amigo) ${ }^{11}$. En nuestro análisis de corpus, sin embargo, nos hemos limitado a computar como sinalefa los casos de unión silábica de medias entre sí y con abierta, o de medias o abierta con cerrada tónica, es decir, los casos que la norma gramatical define como hiato ${ }^{12}$.

Del mismo modo, y siguiendo el criterio de «lenguaje ordinario» expresado por Bello, no todo hiato entre palabras se correspondería con dialefa: combinaciones de vocal media o abierta con cualquier vocal tónica (casos como el de «una hora» o «la isla»), cuya articulación regular se daría separando esas vocales en sílabas distintas, no las hemos computado como fenómeno métrico. Por el contrario, combinaciones que gramaticalmente se corresponden con diptongos, pero que por motivos prosódicos o expresivos se escanden en sílabas distintas, así como la escansión separada de combinaciones entre vocales medias o abierta átonas (casos, por ejemplo, de «mi alma» o «la espera») se han computado como dialefa. En definitiva, todos los casos considerados por Domínguez Caparrós como hiatos desaconsejables, puesto que no reúnen las condiciones prosódicas que favorecen el hiato entre palabras ${ }^{13}$.

\footnotetext{
${ }_{9}^{9}$ T. Navarro Tomás, Métrica española. Reseña histórica y descriptiva, Madrid, Guadarrama, 1974, pp. 1418. K. Spang, Ritmo y versificación [...], ob. cit., pp. 35-38. A. Quilis, Métrica española, ob. cit., pp. 49-52. I. Paraíso, La métrica española en su contexto románico, Madrid, Arco Libros, 2000, pp. 116-7. E. Torre, Métrica española comparada, Sevilla, Universidad de Sevilla, 2000, pp. 30-36. J. Domínguez Caparrós, Diccionario de métrica española, ob. cit., pp. 113-4, 204-5, 400-404.

${ }^{10}$ Real Academia Española, Asociación de Academias de la Lengua Española, Nueva gramática [...], ob. cit., p. 339

${ }^{11}$ T. Navarro Tomás, Arte del verso, Madrid, Visor, 2004, pp. 15-18. R. Balbín, Sistema de rítmica castellana, ob. cit., pp. 67-68, 70, 73. I. Paraíso, La métrica española en su contexto románico, pp. 116-117. J. Domínguez Caparrós, Diccionario de métrica española, ob. cit., p. 402.

${ }^{12}$ Real Academia Española, Asociación de Academias de la Lengua Española, Nueva gramática [...], ob. cit., pp. 332, 335, 337.

${ }^{13}$ J. Domínguez Caparrós, Diccionario de métrica española, ob. cit., p. 204.
} 


\section{VALORACión DE LA DiALEFA POR DIVERSOS TRATADISTAS}

Repasamos a continuación las valoraciones sobre la dialefa que ofrecen diferentes tratadistas de ambos lados del Atlántico en los últimos siglos:

- Domínguez Caparrós ${ }^{14}$ revisa el parecer de estudiosos de la métrica en el siglo XVIII (Vicens, Rengifo, Luzán y Munárriz) y otros del XIX (Hermosilla, Salvá, Bello, Camus, González y García, Coll y Vehí, Marroquín, Caro, y de la Barra) en lo que atañe a los fenómenos métricos; coinciden estos estudiosos en limitar la dialefa a accidentes prosódicos (como acentos relevantes del verso) o a necesidades de lentitud o aspereza en la expresión.

- Sicilia ${ }^{15}$ expresa que la sinalefa, como mecanismo del habla, ha de darse para «evitar aquel efecto desagradable, tanto para el que habla como para el que oye» que produce el hiato, «sonidos hiulcos» que solo proceden si se quiere transmitir «tardanza», «rigor» $\mathrm{O}$ «aspereza».

- Bello ${ }^{16}$ reconoceel uso acertado de la dialefa para la expresión en determinadas circunstancias, aunque enumera más causas a favor de la sinalefa.

- Ya en el siglo xx, Jaimes Freyre ${ }^{17}$ denomina a la dialefa y a la sinalefa, respectivamente, como «excepción» $\mathrm{y}$ «regla» e insiste en que la sinalefa «no es una licencia» sino «una necesidad del idioma».

- Navarro Tomás ${ }^{18}$ observa que en español se evita el hiato por «tendencia general» mediante sinéresis y sinalefa, aunque dicha tendencia está limitada en casos que no se pueden determinar mediante «reglas simples y precisas».

- Balbín ${ }^{19}$ niega la dialefa en concurrencia de vocales átonas, en cuyo caso la sinalefa es «un hecho lingüístico general y necesario en la cadena fónica hispánica», mientras que «la presencia de acento» en alguna de las vocales implicadas «dificulta -aunque en pocos casos llega a impedirla- la formación de las sinalefas». Tras estudiar distintas circunstancias considera la dialefa «numéricamente insignificante».

\footnotetext{
${ }^{14}$ J. Domínguez Caparrós, Contribución a la historia de las teorías métricas en los siglos XVIII y XIX, Madrid, CSIC, 1975, pp. 191-203.

${ }^{15}$ M. J. Sicilia, Lecciones elementales de ortología [...], ob. cit., pp. 214, 218-219.

${ }^{16}$ A. Bello, Principios de ortología y métrica [...], ob. cit., pp. 58-62.

${ }^{17}$ R. Jaimes Freyre, Leyes de la versificación castellana, ob. cit., pp. 94-95.

${ }^{18}$ T. Navarro Tomás, Arte del verso, ob. cit., pp. 13-14.

${ }^{19}$ R. Balbín, Sistema de rítmica castellana, ob. cit., pp. 71.
} 
Reflejo en un estudio de corpus de la evolución y frecuencia de la dialefa en la versificación española

- Spang ${ }^{20}$ considera quela presencia mayoritaria dela sinalefa en la versificación se debe a su carácter natural en el habla; en su opinión, la dialefa constituye una «licencia» métrica.

- Quilis ${ }^{21}$ describe una «clara jerarquización» de los fenómenos métricos dada su frecuencia de uso en la lengua, de modo que la sinéresis y la sinalefa «son fenómenos corrientes y prácticamente constantes en el habla», «casi un hecho de norma lingüística» frente a la dialefa y la diéresis, que «constituyen una excepción».

- Torre $^{22}$ reitera la artificiosidad de la dialefa, que se debe evitar por cacofónica salvo cuando se ajusta al propósito expresivo, y la naturalidad de la sinalefa, que «lejos de ser una licencia» es, por el contrario, «un fenómeno fonético que se da habitualmente en el verso y en el lenguaje ordinario».

- En resumen, diversos tratadistas de la métrica española coinciden en observar la unión silábica como la solución más frecuente y natural a la concurrencia de vocales; la dialefa, en el extremo opuesto, resulta excepcional y, salvo en ciertas circunstancias prosódicas, artificiosa, aunque esta artificiosidad puede adecuarse a determinados propósitos de la expresión.

\section{Presentación de corpus}

Para una aproximación a la realidad de la dialefa en la versificación española, se hace necesario un corpus que cumpla con dos características necesarias: que cubra un espectro suficientemente representativo del patrimonio literario español y que al mismo tiempo resulte manejable.

Entre las diferentes opciones disponibles, hemos hallado tales características en la Antología Cátedra de Poesía ${ }^{23}$, aunque otros volúmenes habrían sido igualmente útiles.

Hemos aislado los versos regulares, un total de 18471, contenidos en dicha antología, y procedido a su análisis métrico para comprobar la proporción de dialefa en tal corpus y contrastarla con las observaciones y afirmaciones de los tratadistas consultados en este trabajo.

Hemos desestimado los versos que no responden a un esquema rítmico de

\footnotetext{
${ }^{20}$ K. Spang, Ritmo y versificación [...], ob. cit., pp. 35-36.

${ }^{21}$ A. Quilis, Métrica española, ob. cit., pp. 52.

${ }^{22}$ E. Torre, «Zeuxis y azeuxis: más sobre vocales en contacto», Rhythmica, 11 (2013), pp. 200-203.

${ }^{23}$ J. F. Ruiz Casanova, Antología Cátedra de Poesía [...], ob. cit., pp. 135-1163.
} 
cantidad silábica predecible, porque los fenómenos métricos (dialefa, diéresis, sinéresis y sinalefa) solo se pueden demostrar con absoluta certeza en versos cuya cantidad silábica esté determinada por un esquema de composición regular. Por tanto, hemos excluido del corpus composiciones medievales cuyos versos presentan vacilación en la regularidad silábica (poesía popular y el Cantar de Mio Cid), y abundantes composiciones del siglo $x x$.

A pesar de ello, la producción de versos regulares comprendida en el s. xx de nuestro corpus supera notablemente a la de los restantes siglos.

El corpus de 18471 versos regulares comprende composiciones fechadas entre el siglo XIII y el xx, de 240 autores diferentes, entre los que el 10\% son americanos ${ }^{24}$. La cantidad de versos regulares por siglo que hemos analizado queda distribuida de la siguiente manera:

1. Siglo XIII: 280 versos, de los que 212 corresponden a composiciones del mester de clerecía. Representan el 1.51\% del total de versos del corpus.

2. Siglo XIV: 655 versos, en su mayoría (384) de autores cultos (Juan Ruiz, Sem Tob de Carrión, Pero López de Ayala, junto con 72 versos del Poema de Alfonso Onceno). Los restantes 271 pertenecen a composiciones del romancero viejo. En conjunto, representan el 3.54\% de los versos del corpus.

3. Siglo xv: 1176 versos que conforman el 6.36\% del corpus.

4. Siglo xvi: 2033 versos. $11 \%$ del corpus.

5. Siglo XVII: 2645 versos. $14.31 \%$ del corpus.

6. Siglo XVIII: 1307 versos. $7.07 \%$ del corpus.

7. Siglo xIx: 2530 versos. $13.69 \%$ del corpus.

8. Siglo xx: 7845 versos. $42.47 \%$ del corpus.

Dado que la cantidad de versos correspondiente a cada siglo no es equitativa, como podemos comprobar en la lista arriba expuesta, junto con los datos totales del análisis ofrecemos también los datos medios entre siglos, para examinar ambas perspectivas:

\footnotetext{
${ }^{24}$ Un anónimo mexicano (s. XVI); fray Miguel de Guevara, Juan del Valle Caviedes y sor Juana Inés de la Cruz (siglo XVII); Esteban Echeverría, Gertrudis Gómez de Avellaneda, José Hernández, José Martí, José Asunción Silva y Amado Nervo (s. XIx); Rubén Darío, Leopoldo Lugones, Delmira Agustini, Gabriela Mistral, Alfonso Reyes, Mariano Brull, César Vallejo, Juana de Ibarbourou, Nicolás Guillén, Pablo Neruda, Gabriel Celaya, Octavio Paz, Concha Zardoya y Nicanor Parra (s. xx).
} 
Reflejo en un estudio de corpus de la evolución y frecuencia de la dialefa en la versificación española

a. Proporción de la dialefa en su presencia total en el corpus, para observar los datos de manera global.

b. Proporción de la dialefa en su presencia por siglo, para atender a su evolución temporal.

Ambas perspectivas nos llevarán a considerar diferentes aspectos, tanto de naturaleza preceptiva (caso de la oposición entre un sistema de versificación foráneo y otro autóctono) como fonética (la pérdida de la aspiración procedente de $f$-inicial latina).

\section{LA DiALEFA EN EL ANÁlisis DEL CORPUS}

Al comenzar nuestro corpus en el siglo XIII exclusivamente con composiciones del mester de clerecía, se hace necesario atender a una práctica particular de este género en lo referente a fenómenos métricos.

El mester de clerecía sigue de manera preceptiva el empleo de la dialefa, o hiato entre palabras, que fuerza a la articulación separada de tales concurrencias de vocales en la escansión de los versos, según comprueban Hanssen ${ }^{25}$, Navarro Tomás ${ }^{26}$ o Uría ${ }^{27}$, entre otros.

Esta práctica, contraria a los hábitos de pronunciación romance, procede de ideas gramaticales regularizadas en la Francia carolingia y propagadas en la Castilla de la temprana Baja Edad Media desde el Estudio General palentino ${ }^{28}$ por medio del verso alejandrino de la Cuaderna Vía, «metro didáctico y narrativo» con el que se aspiraba a difundir la latinidad ${ }^{29}$, tal como esta se entendía tras las reformas carolingias en Francia.

Así, es posible distinguir dos sistemas de versificación diferentes en la España medieval: el autóctono, en el que predomina la sinalefa, y el foráneo, regido por la dialefa ${ }^{30}$. Baehr ${ }^{31}$ define el sistema foráneo como «moda ajena y pasajera».

\footnotetext{
${ }^{25}$ F. Hanssen, «Miscelánea de versificación castellana», Anales de la Universidad de Chile, 97 (1897), p. 230

${ }^{26}$ T. Navarro Tomás, Métrica española [...], ob. cit., pp. 104-105.

${ }^{27}$ I. Uría Maqua, «Gonzalo de Berceo y el Mester de Clerecía en la nueva perspectiva de la crítica», Berceo, 110-111 (1986), p. 11.

${ }^{28}$ I. Uría Maqua, «Gonzalo de Berceo y el Mester de Clerecía [...]», art. cit., p. 14.

${ }^{29}$ F. Rico, «La clerecía del mester», Hispanic Review, 53, 1 (1985), p. 4.

${ }^{30} \mathrm{~J}$. Cano, «La importancia relativa del acento y de la sílaba en la versificación española», The Romanic Review, 22 (1931), pp. 232-233.

${ }^{31}$ R. Baehr, Manual de versificación española, Madrid, Gredos, 1984, p. 59.
} 
La tensión entre ambos sistemas se manifiesta en vacilaciones y presencia de la sinalefa en la lírica culta castellana a pesar de que se aspire al uso único de la dialefa, según comprobaremos a continuación. En opinión de Navarro Tomás ${ }^{32}$, esta presencia de la sinalefa se debe a «natural influencia de la lengua hablada», a la par que la vacilación y el alejamiento de la pronunciación real mediante la dialefa restaron valor lingüístico a las composiciones de clerecía.

Hanssen $^{33}$ señala que se dan casos de sinalefa o elisión (la duda radica en alternancias de grafía, que en unas ocasiones mantiene las dos vocales implicadas y en otras suprime una de ellas), aunque minoritarios frente a la dialefa, en la obra de Berceo, pero que tales casos son más numerosos en el Libro de Alexandre, en el que se encuentran al menos (excluyendo los que Hanssen considera «dudosos») 419 casos de sinalefa, de acuerdo con su cómputo; nuestro propio recuento del fragmento incluido en el corpus ${ }^{34}$, estrofas 2305 a 2320, arroja una proporción de 22 casos de dialefa $(62.85 \%$ del total de fenómenos métricos en el fragmento) frente a 5 de sinalefa (14.28\%); pese a la presencia de sinalefa, la dialefa preceptiva es notablemente superior.

En lo que respecta a Berceo, solo se darían dieciocho casos de dialefa ${ }^{35}$ en la totalidad de versos de Milagros de Nuestra Señora; nuestro propio recuento en los milagros III y XIV, recogidos en nuestro corpus ${ }^{36}$, da, en cambio, una proporción de 31 casos de dialefa $(70.55 \%$ de fenómenos métricos) frente a 9 de sinalefa $(20.45 \%)$. La presencia de sinalefa, en el corpus que estamos manejando, es ligeramente mayor en Berceo que en el Libro de Alexandre. De todos modos, Uría ${ }^{37}$ insiste en que, a pesar de la aparición esporádica de sinalefas, la dialefa se impone como «norma obligada» en las composiciones de clerecía del siglo XIII.

En el siglo XIV, la preceptiva sigue observando el hiato como regla, permitiéndose la sinalefa solo en algunos casos señalados por Pero López de Ayala ${ }^{38}$.

En cualquier caso, Hanssen ${ }^{39}$ registra la creciente presencia de sinalefa tanto en los versos del Arcipreste de Hita durante la primera mitad del siglo XIV (41.79\%, 28

\footnotetext{
${ }^{32}$ T. Navarro Tomás, Métrica española [...], ob. cit., p. 105.

${ }^{33}$ F. Hanssen, «La elisión y la sinalefa en el Libro de Alejandro», Revista de Filología Española, III, 4 (1916), pp. 345-351.

${ }^{34}$ J. F. Ruiz Casanova, Antología Cátedra de Poesía [...], ob. cit., pp. 135-137.

${ }^{35}$ F. Hanssen, «Miscelánea de versificación castellana», art. cit., p. 232.

${ }^{36}$ J. F. Ruiz Casanova, Antología Cátedra de Poesía [...], ob. cit., pp.140-144.

${ }^{37}$ I. Uría Maqua, «Gonzalo de Berceo y el Mester de Clerecía [...]», art. cit, pp. 11-12.

${ }^{38} \mathrm{D}$. Clarke, «Fortuna del hiato y la sinalefa en la poesía lírica castellana del siglo XX», Bulletin Hispanique, 57, 1-2 (1995), pp. 129-130.
}

${ }^{39}$ F. Hanssen, «Notas a la prosodia castellana», Anales de la Universidad de Chile, 107 (1900), pp. 322-324. 
casos, de fenómenos son dialefa preceptiva frente a 53.73\% de sinalefa, 40 casos, en nuestro recuento de las estrofas 44 a 64 y 1348 a 1354 del Libro de Buen Amor tal como aparecen en Ruiz Casanova ${ }^{40}$; Deyermond ${ }^{41}$ estudia la decadencia de la cuaderna vía como medio de expresión y observa que el Libro de Buen Amor, a pesar de su apariencia formal, ya se resiste a quedar enmarcado en la tradición del mester de clerecía) como en los de López de Ayala $(24.56 \%, 14$ casos de dialefa, frente a 61.4\%, 35 casos de sinalefa, en los fragmentos del Rimado de Palacio que comprenden las estrofas 338 a 346 y 616 a 630 presentes en nuestro corpus ${ }^{42}$ ) en el último cuarto, así como entre las composiciones recogidas en el Cancionero de Baena (18.18\%, 2 casos de dialefa, frente a $81.82 \%$, 9 casos de sinalefa, en la única composición de este siglo, de Álvarez de Villasandino, recogida en nuestro corpus $\left.{ }^{43}\right)$.

La influencia francesa se mantendría hasta el siglo $\mathrm{xV}$, en el que autores como Diego del Castillo, Lope de Stúñiga (1 caso de dialefa frente a 3 de sinalefa) $)^{44}$, Juan de Mena ( 1 caso de dialefa frente a 21 de sinalefa ${ }^{45}$ ) y Gómez Manrique (solo 2 encuentros vocálicos susceptibles en un total de 47 versos, ambos resueltos mediante sinalefa ${ }^{46}$ ) evitan por sistema la concurrencia de vocales entre palabras distintas en interior de verso, limitando con ello las posibilidades en que el precepto obliga a realizar hiato ${ }^{47}$.

Por otro lado, se verifica la libre presencia de la sinalefa en las Coplas por la muerte de su padre, de Jorge Manrique ${ }^{48}$, en las que solo hallamos 11 casos de dialefa. De estos casos, 9 se deben a aspiración de la $h$ intervocálica procedente de $f$ latina ${ }^{49}$ : cara hermosa (copla VII), la hermosura (copla IX), se hicieron (también tres ocasiones en las coplas XVI y XVII), que hicieron (copla XXIII), quiero hacer (copla XXV), que hacía (copla Xxx), tanta hazaña (copla XXXIII); el décimo caso, su honra (copla xxx), puede explicarse por monosílabo átono frente a vocal inicial tónica ${ }^{50}$; el décimo primero se da en la concurrencia su halago (copla XXXIV), explicable tal vez por la consonante fricativa $h$ en la raíz árabe de halago.

\footnotetext{
${ }^{40}$ J. F. Ruiz Casanova, Antología Cátedra de Poesía [...], ob. cit., pp. 159-163.

${ }^{41}$ A. Deyermond, Historia de la Literatura Española: La Edad Media, Barcelona, Ariel, 1992, pp. $185-190$.

${ }^{42}$ J. F. Ruiz Casanova, Antología Cátedra de Poesía [...], ob. cit., pp. 179-182.

${ }^{43}$ J. F. Ruiz Casanova, Antología Cátedra de Poesía [...], ob. cit., pp. 227-228.

${ }^{44}$ J. F. Ruiz Casanova, Antología Cátedra de Poesía [...], ob. cit., pp. 230-231.

${ }^{45}$ J. F. Ruiz Casanova., Antología Cátedra de Poesía [...], ob. cit., pp. 193-196.

${ }^{46}$ J. F. Ruiz Casanova., Antología Cátedra de Poesía [...], ob. cit., pp. 197-198.

${ }^{47}$ D. Clarke, «Fortuna del hiato y la sinalefa [...]», art. cit., p. 129.

${ }^{48}$ J. F. Ruiz Casanova, Antología Cátedra de Poesía [...], ob. cit., pp. 199-215.

${ }^{49}$ Véase a este respecto, A. Quilis, Métrica española, ob. cit., p. 50.

${ }^{50}$ E. Benot, Prosodia castellana y versificación, Madrid, Casa Editorial Juan Muñoz, 1892, p. 283.
} 
En definitiva, siguiendo el corpus analizado ${ }^{51}$, en la lírica medieval castellana encontramos la evolución de la presencia de la dialefa entre los restantes fenómenos métricos según indican los datos mostrados en la siguiente tabla:

\begin{tabular}{|c|c|c|c|c|}
\hline & Dialefa & Diéresis & Sinéresis & Sinalefa \\
\hline Siglo XIII & $54.92 \%$ & $15.49 \%$ & $2.11 \%$ & $27.46 \%$ \\
\hline Siglo XIV & $25.37 \%$ & $3.92 \%$ & $4.22 \%$ & $66.46 \%$ \\
\hline Siglo XV & $9.91 \%$ & $9.06 \%$ & $0.56 \%$ & $80.45 \%$ \\
\hline
\end{tabular}

Tabla I. Proporción de fenómenos métricos en la poesía medieval. Corpus Antología Cátedra.

Los siguientes aspectos llaman la atención:

a. La dialefa preceptiva del mester de clerecía es claramente dominante en el siglo XIII, con una presencia significativa de la sinalefa, minoritaria en comparación, pero superior al 25\% del total de fenómenos métricos, y más frecuente que los restantes fenómenos (diéresis y sinéresis).

b. Entre los siglos XIII y XIV se produce una inversión en el empleo de la dialefa con respecto al de la sinalefa; la presencia de esta última incluso es en el XIV notablemente mayor que la de la dialefa en el XIII.

c. En el siglo $\mathrm{xV}$, la sinalefa refleja un incremento con respecto al siglo anterior, mientras que la dialefa sigue reduciendo su presencia (de acuerdo con Navarro Tomás ${ }^{52}$, «los poetas de la segunda mitad del siglo completaron esta evolución liberándose del viejo convencionalismo que tanto había venido perturbando la prosodia del verso desde los tiempos de Berceo»).

En todo caso, nuestros datos concuerdan en general con las observaciones de los autores referidos en las páginas precedentes.

A partir del siglo XVI, el antihiatismo característico del habla se impone sobre el precepto de la dialefa, completamente olvidado en la versificación española hasta las investigaciones de Hanssen ${ }^{53}$.

Devoto $^{54}$ muestra como ejemplo que Hurtado de Mendoza intercala a modo de

\footnotetext{
${ }^{51}$ J. F. Ruiz Casanova, Antología Cátedra de Poesía [...], ob. cit., pp. 135-147, 159-215, 227-240.

${ }^{52}$ T. Navarro Tomás, Métrica española [...], ob. cit., p. 183.

${ }^{53}$ I. Uría Maqua, «Gonzalo de Berceo y el Mester de Clerecía [...]», art. cit., p. 12.

${ }^{54}$ D. Devoto, «Leves o aleves consideraciones sobre lo que es el verso», Cahiers de Linguistique Hispanic Medieval, 7, 7-1 (1982), pp. 38-39.
} 
cita un verso alejandrino de Berceo entre sus endecasílabos, puesto que la escansión de dicho alejandrino, mediante sinalefa y sinéresis en las concurrencias vocálicas, da un cómputo de once sílabas, frente a las catorce sílabas, con dialefa y cesura tras la séptima, en el alejandrino de Berceo «suyo sea el precio; yo seré su obrero».

En los Siglos de Oro, la dialefa pierde toda representatividad anterior entre los demás fenómenos métricos: nuestro recuento del corpus de esta etapa ${ }^{55}$ da la proporción que se muestra en la siguiente tabla:

\begin{tabular}{|c|c|c|c|c|}
\hline & Dialefa & Diéresis & Sinéresis & Sinalefa \\
\hline Siglo XVI & $3.7 \%$ & $2.62 \%$ & $2.39 \%$ & $91.26 \%$ \\
\hline Siglo XVII & $0.82 \%$ & $2.99 \%$ & $2.48 \%$ & $93.69 \%$ \\
\hline
\end{tabular}

Tabla II. Proporción de fenómenos métricos en los Siglos de Oro. Corpus Antología Cátedra.

Los casos de dialefa se reducen significativamente entre el siglo XVI y el XVII. La aspiración de $h$ procedente de $f$ - inicial latina, que como ha explicado Quilis ${ }^{56}$ se mantiene durante el siglo XVI, nos obliga a computar hoy como casos de dialefa numerosas combinaciones de vocales que entonces se hallaban separadas por el cierre silábico de la consonante aspirada; en el siglo XVII, la aspiración oscila según autores: Fernández Andrada, Martín de la Plaza y Fco. de Rioja mantienen la aspiración que fuerza a la dialefa en casos como tu hermosura o mi hado.

En los siglos XVIII y XIX, de acuerdo con los datos del corpus ${ }^{57}$, la dialefa cae hasta una proporción insignificante y la sinalefa se erige como fenómeno métrico dominante. El siglo $x^{58}$, en cambio, refleja un repunte de la dialefa:

\begin{tabular}{|c|c|c|c|c|}
\hline & Dialefa & Diéresis & Sinéresis & Sinalefa \\
\hline Siglo XVIII & $0.48 \%$ & $1.93 \%$ & $1.08 \%$ & $96.49 \%$ \\
\hline Siglo XIX & $0.52 \%$ & $1.28 \%$ & $1.81 \%$ & $96.36 \%$ \\
\hline Siglo XX & $2.03 \%$ & $1.24 \%$ & $2.9 \%$ & $93.81 \%$ \\
\hline
\end{tabular}

Tabla III. Proporción de fenómenos métricos en los siglos XVIII, XIX y xx. Corpus Antología Cátedra.

En concordancia con los datos de los siglos XIX y XX, tratadistas de los últimos

\footnotetext{
${ }^{55}$ J. F. Ruiz Casanova, Antología Cátedra de Poesía [...], ob. cit., pp. 243-452.

${ }^{56}$ A. Quilis, Métrica española, ob. cit., p. 50. Véase también F. J. Herrero, «La aspiración de la h: hiato y sinalefa en poetas de la Edad de Oro», Boletín de la Real Academia Española, LXX (1990), pp. 111-113.

${ }^{57}$ J. F. Ruiz Casanova, Antología Cátedra de Poesía [...], ob. cit., pp. 455-622.

${ }^{58}$ J. F. Ruiz Casanova, Antología Cátedra de Poesía [...], ob. cit., pp. 625-1163.
} 
tres siglos concuerdan a rasgos generales en que los procedimientos de unión silábica (sinalefa y sinéresis) son más frecuentes en la métrica española que los de separación (diéresis y dialefa), tal como encontramos, por ejemplo, en Sicilia ${ }^{59}$, Navarro Tomás ${ }^{60}$, Balbín $^{61}$, Spang ${ }^{62}$, Quiliss ${ }^{63}$, Domínguez Caparrós ${ }^{64}$ y Torre $^{65}$; hasta el punto de que Spang sugiere que a dialefa y diéresis sí se las considere licencias.

\section{ConClusión}

El análisis métrico del corpus estudiado refleja una evolución decreciente de la presencia de la dialefa en la versificación española, desde una posición dominante en el s. XIII hasta una proporción excepcionalmente baja a partir del s. XVII, alcanzando su cota más baja en los ss. XVII, XVIII Y XIX, tras los que se advierte un ligero aumento de su presencia en el s. xx.

Su carácter representativo en el siglo XIII coincide con la práctica versificatoria del mester de clerecía que consistía en escandir forzando la dialefa en los encuentros vocálicos entre palabras; este modo de escansión, importado del extranjero por el Estudio General en Palencia, no arraigó en nuestra métrica al mostrarse contrario a los usos de pronunciación romance, que tienden a la unión silábica entre vocales pertenecientes a palabras distintas mediante la sinalefa, fenómeno métrico contrario a la dialefa. Sin embargo, el valor preceptivo otorgado a la dialefa por el mester de clerecía parece haber restringido el uso de la sinalefa en determinados poetas cultos medievales, que habrían evitado la concurrencia de vocales entre palabras en sus versos para obviar el dilema.

Por otro lado, la aspiración procedente de la finicial latina mantiene numerosos casos de dialefa, considerados desde la articulación de un hispanohablante actual, hasta el s. XVII, en el que este rasgo consonántico desaparece del corpus.

La opinión general entre tratadistas es queel empleo dela dialefa es desaconsejable a menos que se ajuste a propósitos expresivos concretos o a circunstancias prosódicas que favorezcan la articulación de grupos vocálicos en sílabas separadas. Los datos derivados del análisis métrico en este trabajo parecen corroborar este juicio.

\footnotetext{
${ }^{59}$ M. J. Sicilia, Lecciones elementales de ortología y prosodia, Madrid, Imprenta Real, 1832, pp. 219-220.

${ }^{60}$ T. Navarro Tomás, Arte del verso, ob. cit., pp. 14.

${ }^{61}$ R. Balbín, Sistema de rítmica castellana, ob. cit., p. 84.

${ }^{62}$ K. Spang, Ritmo y versificación [...], ob. cit., p. 37.

${ }^{63}$ A. Quilis, Métrica española, ob. cit., p. 52.

${ }^{64}$ J. Domínguez Caparrós, Diccionario de métrica española, ob. cit., pp. 400-401.

${ }^{65}$ E. Torre, «Zeuxis y azeuxis [...]», art. cit., p. 202.
} 


\section{Bibliografía}

BAEHR, R., Manual de versificación española, Madrid, Gredos, 1984.

Balbín, R., Sistema de rítmica castellana, Madrid, Gredos, 1968.

Bello, A., Principios de ortología y métrica de la lengua castellana, Santiago de Chile, La Opinión, 1835.

Benot, E., Prosodia castellana y versificación, Madrid, Casa Editorial Juan Muñoz, 1892.

CANO, J., «La importancia relativa del acento y de la sílaba en la versificación española», The Romanic Review, 22 (1931), pp. 223-233.

Clarke, D., «Fortuna del hiato y la sinalefa en la poesía lírica castellana del siglo $\mathrm{XX}$ », Bulletin Hispanique, 57, 1-2 (1995), pp. 129-132.

Deyermond, A., Historia de la Literatura Española. La Edad Media, Barcelona, Ariel, 1992.

Devoto, D., «Leves o aleves consideraciones sobre lo que es el verso», Cahiers de Linguistique Hispanic Medieval, 7, 7-1 (1982), pp. 5-60.

Domínguez Caparrós, J., Contribución a la historia de las teorías métricas en los siglos XVIII y XIX, Madrid, CSIC, 1975.

Diccionario de métrica española, Madrid, Alianza, 2001.

Hanssen, F., «Miscelánea de versificación castellana», Anales de la Universidad de Chile, 97 (1897), pp. 227-274.

«Notas a la prosodia castellana», Anales de la Universidad de Chile, 107 (1900), pp. 315-335.

, «La elisión y la sinalefa en el Libro de Alejandro», Revista de Filología Española, III, 4 (1916), pp. 345-356.

Herrero, F. J., «La aspiración de la h: hiato y sinalefa en poetas de la Edad de Oro», Boletín de la Real Academia Española, LXX (1990), pp. 111-170.

Jaimes Freyre, R., Leyes de la versificación castellana, La Paz, Imprenta Artística, 1919.

Navarro Tomás, T., Métrica española. Reseña histórica y descriptiva, Madrid, Guadarrama, 1974.

Arte del verso, Madrid, Visor, 2004.

PARAíso, I., La métrica española en su contexto románico, Madrid, Arco Libros, 2000.

QuiLis, A., Métrica española, Barcelona, Ariel, 1984.

Real Academia Española, Asociación de Academias de la Lengua Española, Nueva gramática de la lengua española. Fonética y fonología, Barcelona, Espasa, 2011.

Rico, F., «La clerecía del mester», Hispanic Review, 53, 1 (1985), pp. 1-23.

Ruiz Casanova, J. F., Antología Cátedra de Poesía de las Letras Hispánicas, Madrid, Cátedra, 2012.

SiciLiA, M. J., Lecciones elementales de ortología y prosodia, Madrid, Imprenta Real, 1832.

SpANG, K., Ritmo y versificación. Teoría y práctica del análisis métrico y rítmico, Murcia, Universidad de Murcia, 1983. 
Antonio Alcoholado Feltstrom

TORRE, E., El ritmo del verso: estudios sobre el cómputo silábico y la distribución acentual a la luz de la métrica comparada, en el verso español moderno, Murcia, Universidad de Murcia, 1999.

__ Métrica española comparada, Sevilla, Universidad de Sevilla, 2000.

, «Zeuxis y azeuxis: más sobre vocales en contacto», Rhythmica, 11 (2013), pp. 187-205.

URíA MAQUA, I., «Gonzalo de Berceo y el Mester de Clerecía en la nueva perspectiva de la crítica», Berceo, 110-111 (1986), pp. 7-20. 